\title{
PERANCANGAN DAN IMPLEMENTASI APLIKASI SISTEM INFORMASI MANAJEMEN PERTANDINGAN DAN PENILAIAN ELEKTRONIK KEMPO
}

\author{
Rudy Gunawan \\ Program Studi Teknik Elektro \\ Universitas Sangga Buana-YPKP Bandung \\ rgunawan28@gmail.com
}

\begin{abstract}
ABSTRAK
Setiap penyelenggaraan pertandingan olahraga tentu mengharapkan pertandingannya sukses sesuai jadwal yang telah direncanakan. Penyelenggaraan pertandingan ingin dicapai secara efektif dan efisien. Untuk mencapai tujuan tersebut maka diperlukan pegelolaan yang baik dan berkesinambungan mulai dari masa persiapan, pendaftaran peserta, pertemuan teknis dan selama berlangsungnya pertandingan. Shorinji Kempo adalah cabang olahraga beladiri anggota KONI yang telah dipertandingakan secara resmi di arena PON dan SEA Games. Pada cabang olah raga kempo dipertandingan dua jenis pertandingan yaitu embu(kerapihan teknis) dan randori(fight). Dua jenis ini mempunyai cara penilaian berbeda yaitu scoring juri pada nomor embu (kerapihan teknis) dan kalah menang pada pertandingan randori (fight). Pada pertandingan embu penilaian perserta harus segera dihitung dan ditentukan urutan rangking. Hal ini akan menentukan peserta lanjut atau tidak ke babak selajutnya. Pertandingan Kempo biasanya dilakukan di beberapa lapangan (court) yang berbeda yang berjalan secara paralel dengan juri yang berbeda. Untuk menjaga efesien pertandingan maka pertandingan harus berlanjut secara kontinyu tanpa jeda terlalu lama. Untuk ini proses perhitungan scoring dan keputusan harus dilakukan dengan segera. Aplikasi sistem informasi pertandingan dan penilaian elektronik akan membantu proses pertandingan berjalan dengan efektif dan efesien. Aplikasi akan menjaga integritas data informasi pertandingan secara akurat secara terpusat. Aplikasi ini memungkinkan hasil penilaian diumumkan secara real time, hal ini akan menambah fairness pertandingan. Sistem informasi Manajemen pertandingan dan penilaian Elektronik akan membantu kelancaran pertandingan dan menjaga integritas dan keakuratan data yg tersimpan terpusat. Dengan cara ini laporan pertandingan akan lebih mudah. Sistem aplikasi ini akan menjamin penyelenggraan pertandingan yang effesien dan efektif.
\end{abstract}

Kata kunci: Sistem Informasi, Pertandingan, Kempo

\section{PENDAHULUAN}

\footnotetext{
Setiap penyelenggaraan pertandingan olahraga tentu mengharapakan pertandingannya sukses dan selamat sesuai jadwal yang telah direncanakan tentunya ingin dicapai secara efektif dan efisien. Untuk mencapai itu diperlukan suatu langkah dan metode yang terencana dan terukur.

Pada suatu event/pertandingan ada banyak pihak/faktor yang mempengaruhi kelancaran sebuah pertandingan diantaranya:
}

1. Sumber daya manusia panitia pelaksanaan

2. Kontingen peserta/pertandingan
3. Peraturan pertandingan

4. Perlengkapan yang mencukupi

5. Sistem pertandingan.

6. Jadwal pertandingan

7. Sistem penilaian kontestan.

8. Keep track pertandingan setiap waktu.

9. Laporan hasil pertandingan

Ada 4 tahap atau langkah agar penyelenggaraan pertandingan berjalan dengan lancardan baik, yaitu :

1. Tahap persiapan (jauh pertandingan)

2. Tahap dekat pertandingan

3. Tahap berlangsungnya pertandingan

4. Tahap selesai pertandingan 


\subsection{Pertandingan Shorinji Kempo}

Shorinji Kempo adalah cabang olahraga beladiri anggota KONI yang telah dipertandingakan dia arena PON dan SEA Games

Pada cabang olah raga ini terdapat 2 jenis pertandingan yaitu:

1. Embu (kerapihan teknis).

2. Randori (tarung bebas/Fight)

Dua jenis pertandingan dibagi menjadi beberapa nomor sesuai katagori yang dimainkan. Sebagai contoh jenis embu dapat dibagi menjadi katagori gender, tingkatan dan jumlah regu. Contoh:

1. Embu beregu putra (4 orang per grup)

2. Embu berpasangan tingkat 1 DAN putri ( 2 orang per grup).

Sistem penilaian tiap jenis pun berbeda, untuk jenis embu bentuknya adalah penjurian seperti beauty contest maka nilai tertinggi akan memenangkan pertandingan.

Sementara untuk jenis randori penilaiannya adalah kalah menang. Pada nomor pertandingan dengan jenis randori dapat dimasukan ke sistem/skema pertandingan tertentu( sistem gugur/kompetisi).

\subsection{Sistem Informasi Manajemen Pertandingan Kempo}

Pada pelaksanaan pertandingan tidak ada ruang untuk berbuat kesalahan/kekeliruan. Setiap kesalahan harus dibayar dengan waktu dan kepercayaan para kontestan/peserta. Oleh karena itu penerapan sistem aplikasi informasi manajemen pertandingan akan sangat menolong untuk dapat menjaga agar pertandingan akan berjalan sesuai yang direncanakan. Sistem penilaian elektronik yang diterapkan sekaligus adalah sistem penilaian terbuka terutama pada cabang pertandingan yang sifatnya adalah beauty contest oleh juri. Sehinga akan menambah fair play dari suatu penilaian juri.

\subsection{Pembatasan Masalah}

Dalam perancangan ini yang akan dibuat adalah berupa sistem informasi dari manajemen pertandingan dan penilaian secara elektronik.

Sistem informasi manajemen elektronik yang dikembangkan ini termasuk dalam tahap pertandingan sedang berlangsung dan tahap pertandingan selesai berupa laporan.

\section{MANAJEMEN PERTANDINGAN KEMPO}

Untuk menjaga keberhasilan dari suatu event pertandingan perlu dilakukan manajemen pertandingan yang memadai baik itu menggunakan elektronik ataupun tidak.

Proses manajemen pertandingan dimulai dari sebelum pertandingan (persiapan), pertemuan teknis(technical meeting) dan proses selama pertandingan berlangsung.

\subsection{Proses Persiapan}

Proses persiapan dimulai dengan seting manajemen pertandingan dimulai dengan seting event, nama, tempat lokasi pertandingan, disusul dengan nomor dan jenis pertandingan yang akan dilaksanakan, kemudian mendaftarkan tim peserta dan peserta pertandingan. Pengisian nama peserta ke masing-masing nomor pertandingan tertentu. Dan yang terakhir adalah memasukan nama wasit ke dalam database pertandingan.

\subsection{Proses Pertemuan Teknis}

Persiapan pertandingan dimulai dari pertemuan teknis para manajer tim untuk menentukan undian atau skema pertandingan. Pada tahapan ini akan ditentukan urutan penampilan pada nomor embu. Memasukan posisi peserta pada skema pertandingan pada nomor randori. Selanjutnya pada persiapan akhir akan dibuat jadwal pertandingan. 


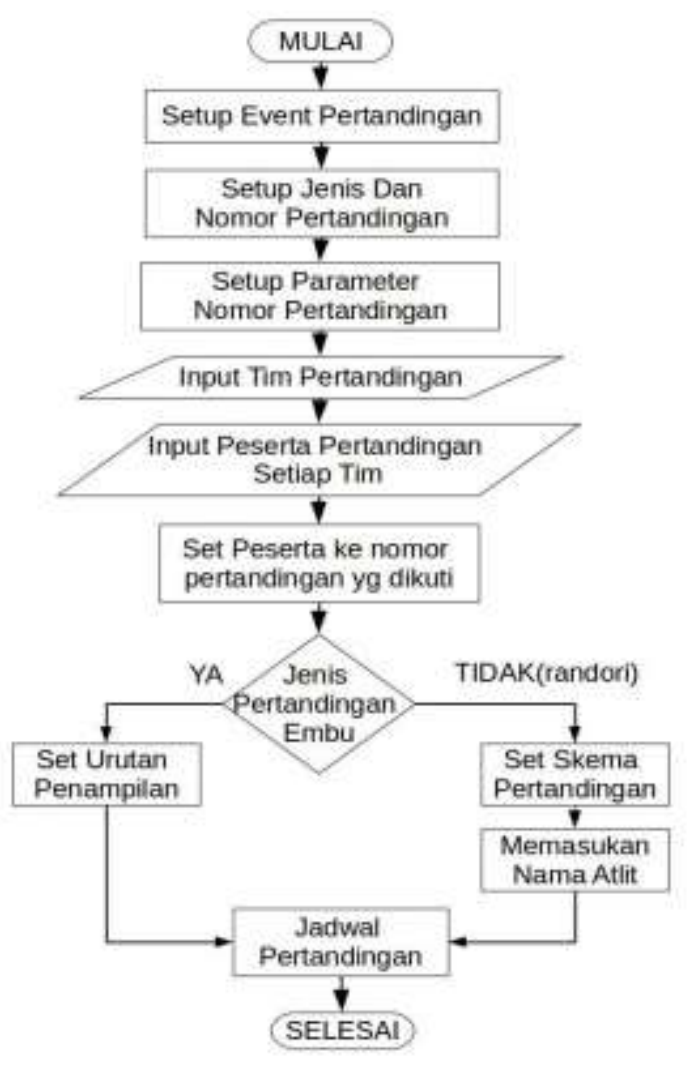

Gambar 1. Diagram alir seting pertandingan

\subsection{Penyusunan Jadwal Pertandingan}

Jadwal pertandingan disusun sedemikian agar dapat diperkirakan lama waktu yang dibutuhkan dan menghindari adalanya overlapping atlit yang mungkin bermain di beberapa nomor yang berbeda.

\subsection{Proses Pertandingan}

Manajemen pertandingan akan menyediakan daftar penampil sesuai dengan jadwal yang telah diterbitkan.

Pada pertandingan embu manajemen pertandingan akan mencatat penilaian juri terhadap setiap peserta penampil. Pada pertandingan randori manajemen pertandingan akan mencatat hasil pertandingan dan memperbaharui skema pertandingan.

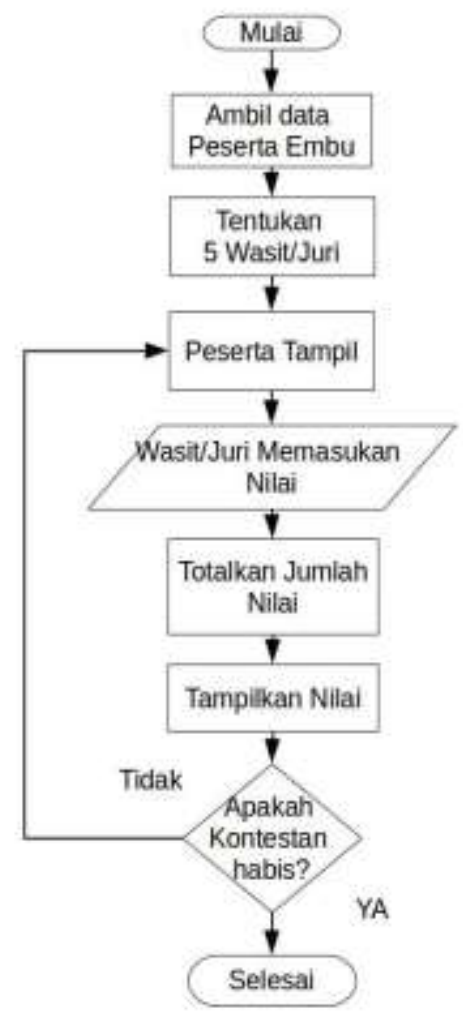

Gambar 2. Diagram alir seting penilaian embu

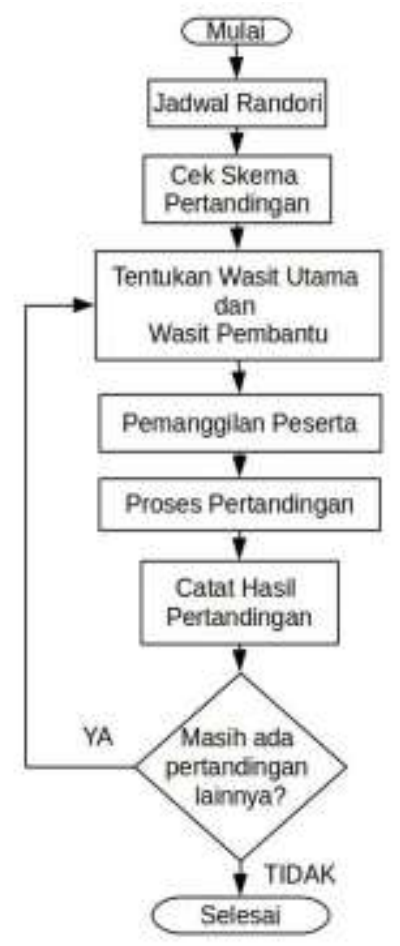

Gambar 3. Diagram alir penilaian kempo randori 
Pada pertandingan randori manajemen memanggil perserta sesuai jadwal dan akan mencatat hasil pertandingan

\subsection{Penilaian Wasit}

Pada pertandingan kempo akan diwasiti oleh 5 orang wasit. Posisi juri/wasit adalah mengelilngi arena pertandingan. Ada perbedaan antar jenis pertandingan embu dan randori. Pada pertandingan embu semua wasit dalam posisi duduk mengelilingi arena pertandingan, sementara dalam pertandingan randori empat wasit duduk mengeleilingi arena yang disebut dengan wasit pembantu dan satu wasit utama berdiri ditengah arena.

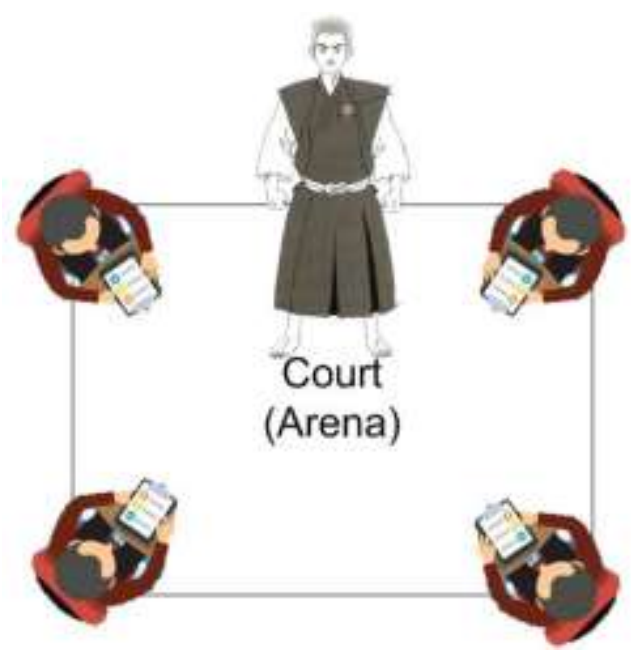

Gambar 4. Posisi wasit randori

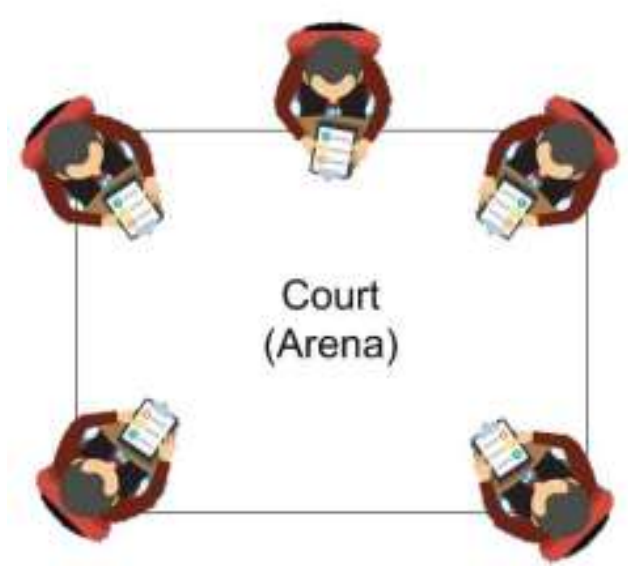

Gambar 5. Posisi wasit embu

\section{PERANCANGAN APLIKASI SISTEM MANAJEMEN PERTANDINGAN KEMPO}

\subsection{Modul Aplikasi}

Perancangan aplikasi manajemen elektronik akan mengadopsi bisnis proses manajemen pertandingan manual dan .ditambah dengan penilaian wasit pertandingan secara elektronik untuk pertandingan embu dan randori. Oleh Karena itu aplikasi dibagi menjadi beberapa modul-modul seperti:

1. Manajemen Event Pertandingan

2. Manajemen Tim dan Peserta Pertandingan

3. Manajemen Nomor Pertandingan

4. Manajemen Asiisgn Peserta Nomor pertandingan

5. Manajemen Jadwal Pertandingan

6. Manajemen Wasit/Juri

7. Manajemen Penilaian Pertandingan Embu

a. Manajemen Court

b. Manajement Display Terminal

c. Manajement Gadget Wasit

8. Manajemen Penilaian Pertandingan Randori
a. Manajemen Court
b. Manajement Display Terminal

Ada 4 jenis user yang berhubungan langsung dengan aplikasi ini yaitu:

1. Adminstrator Pertandingan

2. Panitera court/lapangan

3. Wasit Embu

4. Display Terminal

\subsection{Devais (Gadget) Wasit}

Untuk pertandingaan jenis embu penilaian para juri ada lima wasit yang ditempatkan disekeliling arena. Untuk itu diperlukan devais elektronik yang dapat memberikan masukan nilai secara nirkabel. Hal ini diperlukan untuk menghindari banyaknya kabel ke arena pertandingan. Devais yang dipilih adalah sebuah computer tablet.

\subsection{Development Tools}

Aplikasi Sistem Informasi Manajemen pertandingan dibangun berbasiskan web. Dengan spesifikasi konfigurasi sebagai berikut: 
1. Sistem Operasi berbasis Linux sebagai server.

2. Apache Webserver.

3. Database Mysql

4. Bahasa pemrograman PHP, Javascript

\subsection{Database}

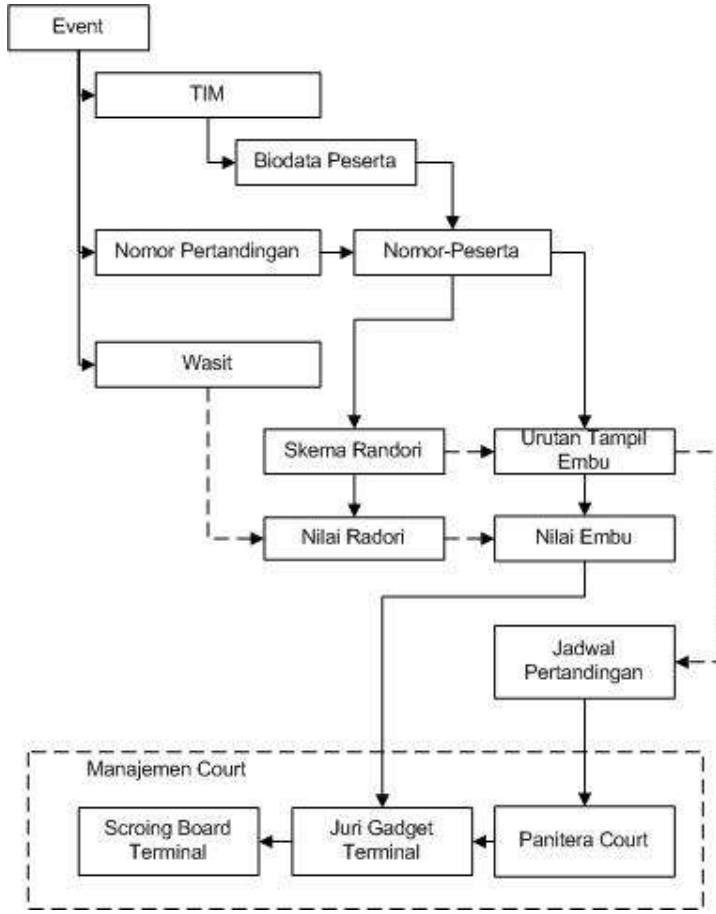

Gambar 6. Diagram database aplikasi SIM Pertandingan

\section{IMPLEMENTASI APLIKASI SISTEM PERTANDINGAN KEMPO}

\subsection{User Interface}

Semua user interface yang dikembangkan diaplikasi ini adalah berbasikan web. Untuk ini yang diperlukan hanya sebuah web browser untuk dapat akses kedalam sistem ini. Pemilihan teknologi ini memungkinkan aplikasi berjalan pada semua jenis platform sistem operasi dan semua jenis web browser.

\subsubsection{User Interface Administrator} Sebagai administrator pertandingan mempunyai privileges paling tinggi.

\subsubsection{User Interface Panitera}

Merupakan pengendali pertandingan di masing-masing court, hanya dapat menampilkan dan mejalankan pertandingan tidak mempunyai privileges untuk merubah sesuatu.

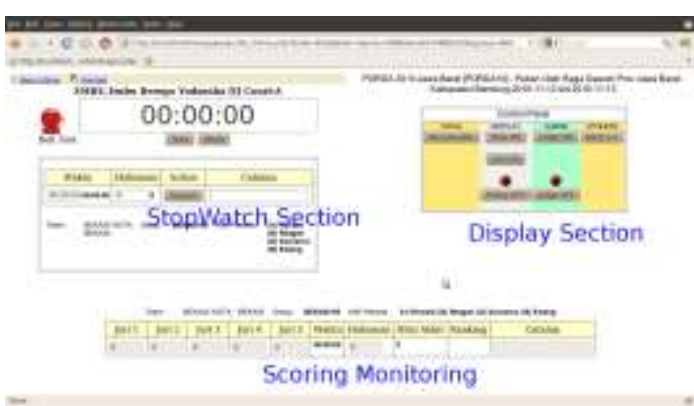

Gambar 7. User interface panitera Embu

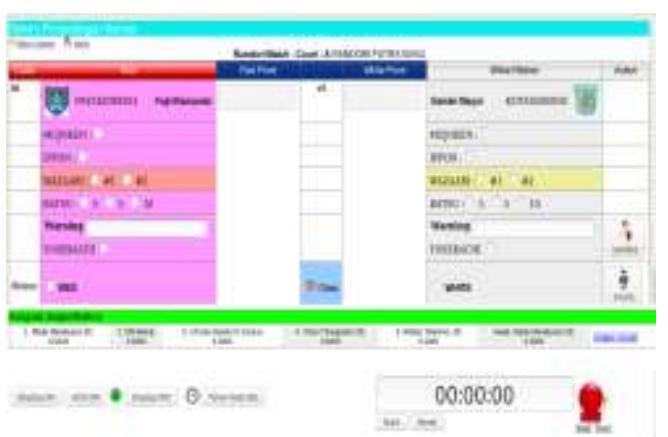

Gambar 8. User interface panitera Randori

\subsubsection{User Interface Wasit}

Adalah user interface unutk easit dalam menilai pertandingan embu.

\subsubsection{User interface Terminal Display}

Untuk menghubungkan terminal display ke dalam sistem ini.

\subsection{Pertandingan Embu}

Pada pertandingan nomor embu para juri/wasit akan dibekali oleh komputer tablet sebagai media penilaian yang lansung tersambung dengan aplikasi pertandingan. Untuk penilaian embu ada 10 item yang terdiri dari 6 adalah berkaitan dengan penilaian teknik dan 4 item berkaitan dengan penilaian ekspresi, dan keindahan. Semua nilai yang masuk akan di urutkan dari yang terbesar sampai terkecil dari masing-masing wasit. Nilai yang tertinggi dan terendah akan dicoret. 
Jadi akan dijumlahkan dari nilai 3 orang wasit saja.

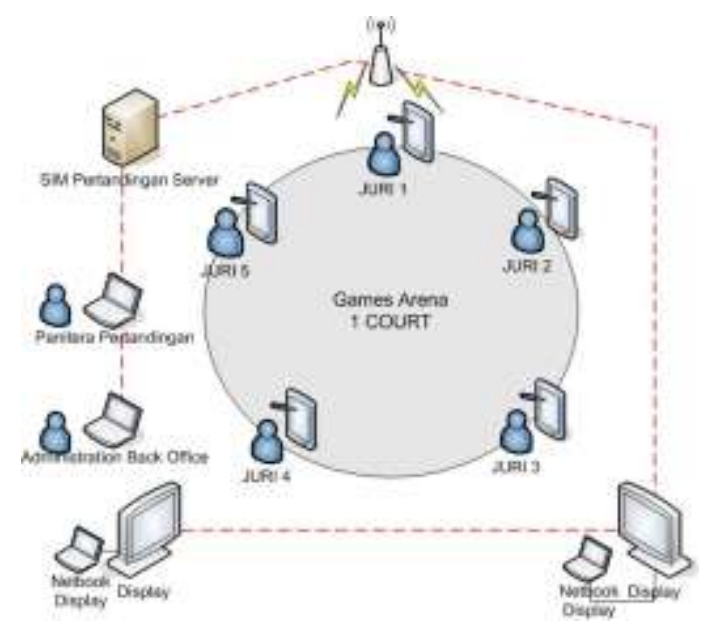

Gambar 9. Konfigurasi penilaian wasit embu

\subsection{Jumlah Lapangan Pertandingan (Court)}

Pada pertandingan kempo biasanya akan terdiri dari lebih satu court (lapangan), Untuk itu SIM Pertandingan akan memastikan data nilai tidak akan saling tumpang tindih dengan court lainnya.

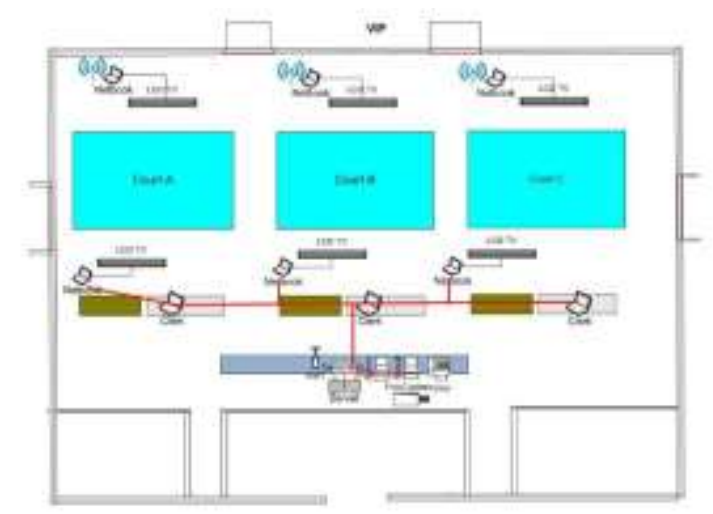

Gambar 10. Lapangan (Court) Pertandingan

\subsection{Panitera Embu}

Pada setiap pertandingan maka semua pertandingan akan dikendalikan oleh panitera di meja court, Panitera akan melihat jadeal dan pertandingan apa hyang akan di eksekusi setiap waktu. Panitera ini akan memastika baha form penilaian benar yang dikirim ke devais para wasit.

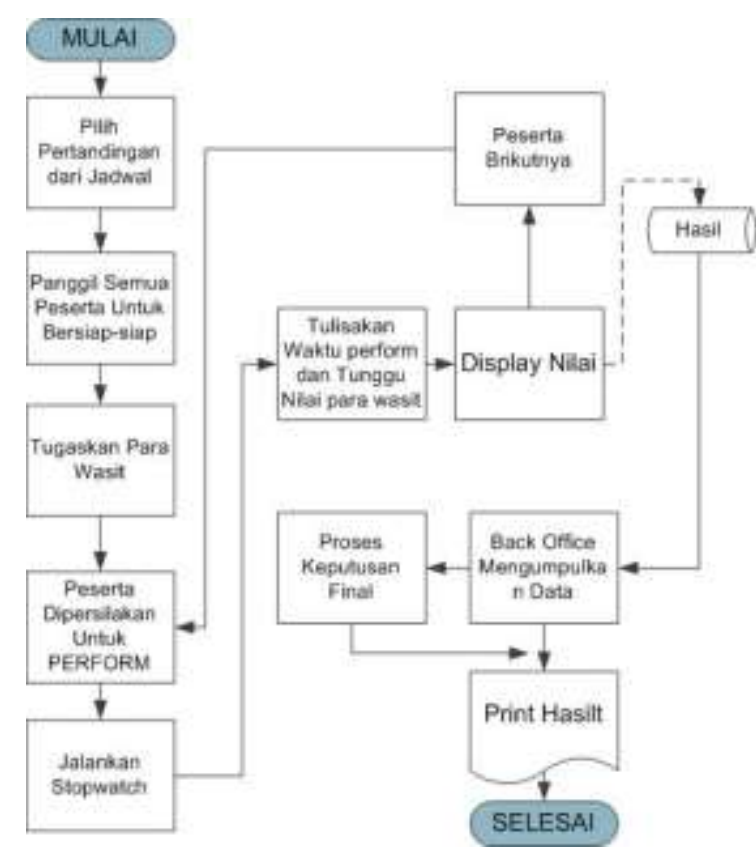

Gambar 11. Proses kerja panitera embu

\subsection{Register Wasit Embu}

Pada pertandingan embu semua form penilaian wasit akan di kendalikan oleh server. Oleh karena itu para wasit diharuskan login lewat devais computer tablet-nya. Data yang harus di masukan adalah nama wasit, court dan ututan wasit.

Wasit yang berhasil login akan pada posisi Siap/Ready. Form penilaian akan dikirm dari server atas kendali dari panitera court yang bersangkutan. Data kontestan yang dikirim adalah nama kotenstan, teknik yang dimainkan. Wasit akan menilai dan setelah selesai akan mengirimkan semua nilai ke server. Setelah posisi ini layar para wasit akan di kunci sampai panitera mengirim semua nilai ke layar display besar. 


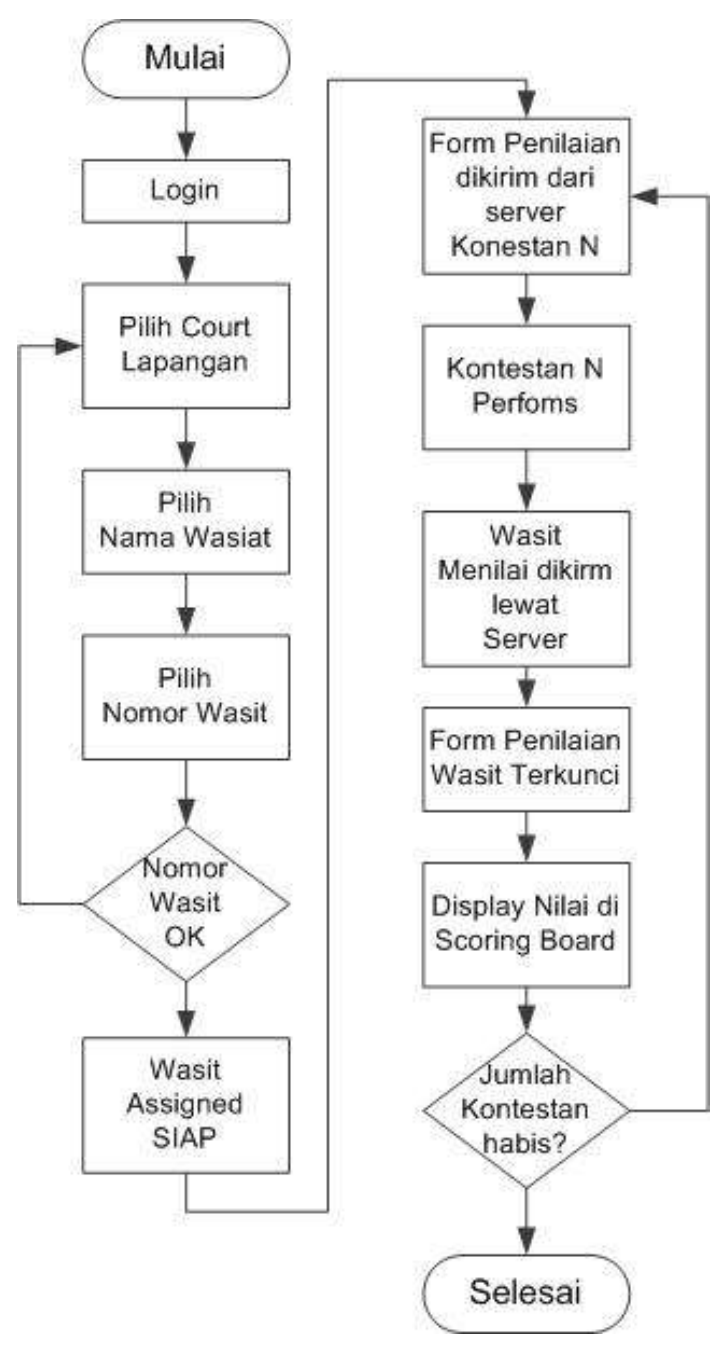

Gambar 12. Diagram alir wasit

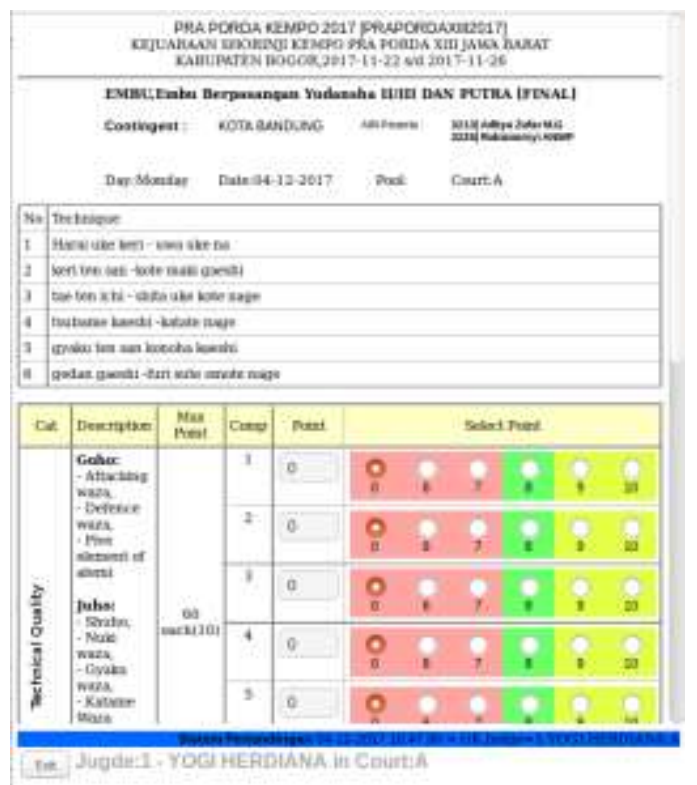

Gambar 13. Tampilan layar formulir penilaian

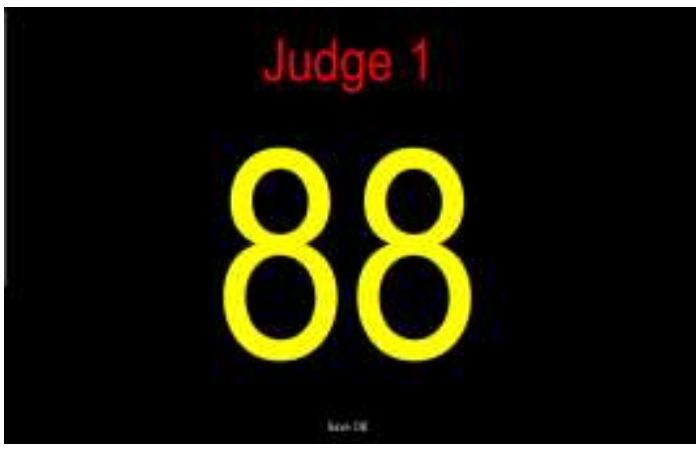

Gambar 14. Tampilan layar setelah penilaian

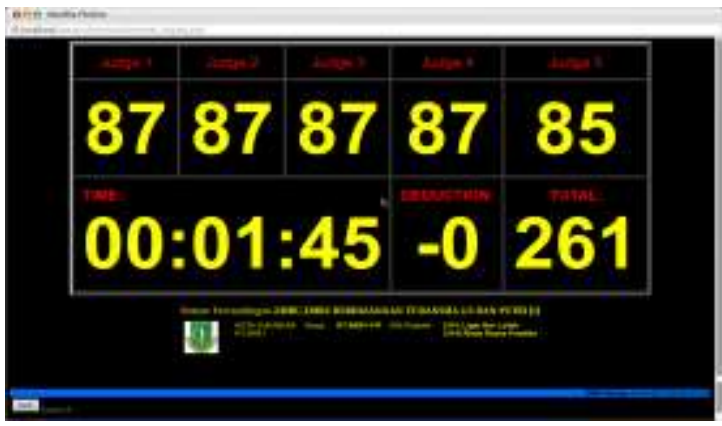

Gambar 15. Tampilan layar terminal

\subsection{Sistem Informasi Pertandingan (Live in Action)}

Sistem informasi manajemen pertandingan dan penilaian elektronik telah digunakan pada beberapa event pertandingan baik itu skala daerah, nasional maupun internasional. Pada setiap event pertandingan selalu dilakukan perbaikan dan penyempurnaan yang dilakukan berulang-ulang sehingga mencapai tahap seperti sekarang ini.

1. Sea Games XXVI, Jakarta,Indonesia 2011 (Penilaian Elektronik)

2. Kejuaraan Bogor Open 2013

3. Sea games XXVII, Yagoon, Myamar 2013, (SIM Pertandigan)

4. PORDA JABAR XII, Kab Bekasi, 2014

5. PRA PON XIX 2015

6. Pekan Olah Raga Nasional XIX 2016

7. PRA PORDA JABAR XIII, Kab Bogor, 2017 


\section{PENUTUP}

Sistem Informasi Manajemen dan penilaian elektronik akan membantu pengelola pertandingan dalam melancarkan proses/ aktifitas pertandingan yang berlangsung. Aplikasi akan membuat data yang terintegrasi akan dapat dimonitor oleh manajer pertandingan sehingga dapat melakukan tindakan yang diperlukan dengan segera.

Penilaian elektronik akan membantu para wasit dalam melakukan penilaian dan mengurangi kesalahan manusia dalam perhitungan, sehingga data yang masuk akan akurat.

Penayangan penilaian secara langsung akan disaksikan langsung oleh penonton dan peserta hal ini akan menambah transparanssi dan fairness penilaian dan netralitas penjurian/perwasitan.

Sistem aplikasi ini secara langsung dapat menaikan kualitas penyelenggaran dari suatu pertandingan yang efesien dan efektif.

\section{DAFTAR PUSTAKA}

[1] Kurniawan,Rachel Dkk ,"Interaksi Aplikasi Android dengan JSON Web Service berbasis PHP”. .Buku Kita, 2016.

[2] M. Rudyanto Arief, "Pemrograman Web Dinamis Menggunakan PHP dan MySql, $\quad$ (STIMIK AMIKOM), Andipublishing, 2011.

[3] PB.PONXIX JABAR,'Technical Handbook Kempo". Panpel Cabor Kempo, PON XIX Jawa Barat,2016. 